\title{
Deterioration of School Performance as a Consequence of Parasitic Infestation in Menoufiya Governorate
}

\author{
WESAM S. MORAD, M.D.* and ALIF A. ALLAM, M.D.** \\ The Departments of Epidemiology \& Preventive Medicine* and Pediatric Hepatology**, National Liver Institute, \\ Menoufiya University, Menoufiya, Egypt.
}

\begin{abstract}
Background: Worm infestation is a major problem in children from developing countries due to bad hygienic conditions. It produces nutritional deficiencies and anemia in children, especially when hookworm infestation is present. Infections impair children's growth and development. Studies have shown associations between helminthes infection and under nutrition, iron deficiency anemia, stunted growth, and poor school attendance.
\end{abstract}

Aim of Study: This study aims to assess the relation between parasitic infestation in primary school children and its effect on school performance.

Patients and Methods: The nutritional state of children was assessed by anthropometric measures, clinical examination and laboratory investigation such as hemoglobin (HB) level. The parasitic infestation was assessed by stool and urine analysis, also school performance was assessed by Intelligence quotient (IQ), school achievement and school attendance. Study done from the end of August 2016 to the end of November 2018 in Shebin El-Kom Center and Berkit Sabaa Village, Menoufiya Governorate.

Results: This study showed high prevalence of parasitic infestation in rural $67.5 \%$ than urban $58.5 \%$ with high prevalence of entameba histolytica , ascaris, giardia, oxyuris, mixed infection while hymenolepis nana, tricuris tricura, anclystoma duodenale. Strongyloides stercoralis and schistsoma mansoni present only in rural with low incidence. There was no statistical significant difference between urban and rural school children regarding anthropometric measures including (body weight, height and head circumference) and between infected and non infected except for weight, there was statistical significant difference between non infected children compared to infected. Also there was statistically significant difference in hemoglobin level between urban compared to rural and between infected children compared to non infected as the prevalence of anemia was a higher in rural compared to urban and among infected children compared to non infected. There was statistical significant difference in school performance parameters including (I.Q level and school achievement) between urban compared to rural and infected children compared to non infected students.

Correspondence to: Dr. Wesam S. Morad,

E-Mail: wesammorad@yahoo.com
Conclusions: It is evident that there is correlation between parasitic infestation and poor children cognitive function (school performance) and growth.

Recommendations: All members dealing with children such as, teachers, pediatric clinics and family physician in family health units and centers for eradication and treatment of all affected children with parasite should be integrated to improve children school performance. Programs for prevention and control of parasitic infection and school performance disorders must be prioritized.

Key Words: Parasitic infestation - Cognitive function - School performance - Anthropometric measures - School children.

\section{Introduction}

HELMINTHES infestations are widely distributed all over the world especially in the developing countries, Egypt is one of them, it is highly infested by all of the categories of helminthes and especially the primary school aged children [1]

Worms cause hyperactive behavior, learning problems, depression, or attention deficits by making children miserable on the inside. Parasites rob the body of needed nutrients which in-turn affects behavior [2] .

Asessing the effect of parasitic infestations on the school children behavior and intelligence and school performance. Heavy worm burdens are associated with impaired cognitive function and delays in psychomotor development. Helminthes infection adversely influences attendance, enrollment, and school completion. The presence of parasites leads to other health-and nutrition-related problems that have adverse consequences for school achievement [3]

In the early phase (4-16d after egg ingestion), respiratory symptoms result from the migration of larvae through the lungs. Classically, these symp- 
toms occur in the setting of eosinophilic pneumonia (Löffler syndrome), fever, non productive cough, dyspnea, wheezing. In the late phase (6-8 wk after egg ingestion), gastrointestinal symptoms occur. Diffuse or epigastric abdominal pain, nausea, vomiting, fever, jaundice (in biliary obstruction), cachexia (due to malnutrition) and mental retardation [4].

Strongyloidiasis can become chronic and then become completely asymptomatic. Giving proton pump inhibitors (PPI), greatly reduces the $\mathrm{HCl}$ content of the stomach and allows the strongyloides to thrive. That is why often individuals with strongyloidiasis develop worse epigastric distress when placed on PPI's [5].

Patients are often asymptomatic. Worms may be incidentally discovered when worms are found in the perineal region. If patients are symptomatic, pruritus ani and pruritus vulvae are common presenting symptoms. Restlessness during sleep is noted by the parents of many children. Visual sighting of a worm by a reliable source (e.g., a parent) is usually accepted as evidence of infestation and grounds for treatment [6].

Many individuals do not experience symptoms. The first symptom of the disease may be a general ill feeling. Within twelve hours of infection, an individual may complain of a tingling sensation or light rash, commonly referred to as "swimmer's itch", due to irritation at the point of entrance. Other symptoms can occur two to ten weeks later and can include fever, aching, cough, diarrhea, or gland enlargement [7]

There are no specific symptoms or signs of hookworm infection Coughing, chest pain, wheezing, and fever will sometimes be experienced by people who have been exposed to very large numbers of larvae. Epigastric pains, indigestion, nausea vomiting, constipation, and diarrhea can occur early or in later stages as well, although gastrointestional symptoms tend to improve with time [8]

Asymptomatic infections are common following ingestion of the parasite. E dispar does not cause invasive disease or antibody production. As many as $90 \%$ of E histolytica infections are also asymptomatic. The infection is self-limited but may be recurrent. Only antigen detection tests can distinguish between $\mathrm{E}$ histolytica and $\mathrm{E}$ dispar.

Most individuals with G lamblia are probably asymptomatic. Giardiasis produces symptoms more often in children than in adults. Symptoms develop in an estimated $40-80 \%$ of infected children. Clin- ical signs and symptoms, diarrhea, malaise, weakness, abdominal distention, flatulence, abdominal cramps, nausea ,weight loss, vomiting, low-grade fever (infrequent), various neurologic symptoms (eg. irritability, sleep disorder, mental depression, neuroasthenia), urticaria [9]

Most standardized tests are not designed to evaluate the individualized growth and development taking place in the classroom. Children taking these tests are assessed on isolated skills in ways that are unfamiliar to them, and the test results often do not reflect children's personal experiences or knowledge. In recent years, however a new approach to assessment has been gaining acceptance among early childhood and primary grade teachers. Known as "performance" assessment [10].

\section{Benefits of performance assessment:}

A system of developmental checklists, portfolios of children's work, and summary reports, when used together, can help you to recognize that children can express what they know and can do in many different ways, to evaluate progress as well as performance, to evaluate the "whole child", to involve children in the process of assessing their own growth, to establish a framework for observing children that is consistent with the principles of child development, to contribute to meaningful curriculum planning and the design of developmentally appropriate educational interventions, to give parents specific, direct, and understandable information about their child and to collaborate with other teachers, thus enhancing your own professional skills [11].

\section{School performance problems:}

There are many reasons for teens to underperform at school, lack of motivation to do well, problems at home or with peers, poor work habits or study skills, emotional and behavior problems, learning disabilities (such as dyslexia), attention deficit hyperactivity disorder, mental retardation or below average intelligence, medical problems, including anxiety and depression, children with sleep problems, such as obstructive sleep apnea, or inadequate sleep, can have problems in school, usually secondary to attention problems and daytime sleepiness [12].

Parasitic infection is one of the most common infections in the world. The majority of cases occurs in people living in developing countries and is visually common and most intense among school-aged children. Infections in children affect their health, growth, nutritional status and mental development [13]. 
Among school aged populations, helminthes infection generates very high levels of morbidity despite of the relatively limited mortality associated with the condition. Severe hookworm infection is associated with impaired mental function as well as such educational outcome measures as absenteeism, under enrollment. Thus, helminthes infection appears to constitute a very real barrier to children progress in school [14]

Infestation with roundworm, hookworm and whipworm often affects the nutritional state of the children and school performance because it can stunt growth, decrease physical activity and cause poor mental development [15].

One third of the world population is infected with one or more species of intestinal helminthes and public health specialists are concerned that these infections impair children growth and development. Studies have shown associations between helminthes infection and under nutrition, iron deficiency anemia, stunted growth, poor school attendance and poor performance in cognition tests [14] .

In general, helminthic infection is linked to poor mental function, educational attainment and learning ability. It is unclear, however, whether the relationship is causal or confounded by intervening socioeconomic variables.

Nevertheless, roundworm, whipworm and hookworm are all considered to exert heavy negative influence on learning attitudes and moderate negative influence on school attendance [16].

\section{Aim of work:}

The present study was designed to determine if there is an association between parasitic infestation of school children and their cognitive function or their school performance.

The main objective was: To is to assess the relation between parasitic infestation in primary school children and its effect on school performance in Berkit El Saba center in Menoufiya Governorate.

This will be fulfilled through: (I) Assessing nutritional state of children by anthropometric measures, clinical examination and laboratory investigation hemoglobin (HB) level, (II) Assessing parasite infestation by stool and urine analysis. And (III) Assessing school performance by IQ, assessing school achievement and school attendance.

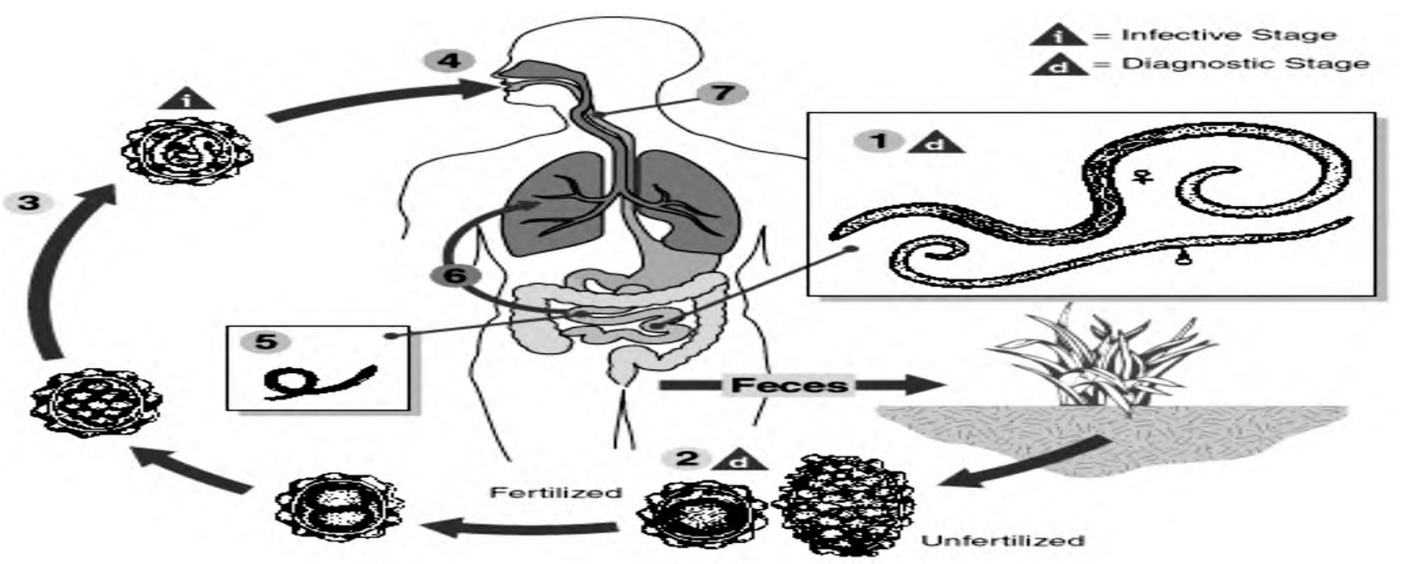

Fig. (1): Life cycle of ascaris (http://www.dpd.cdc.gov/dpdx).

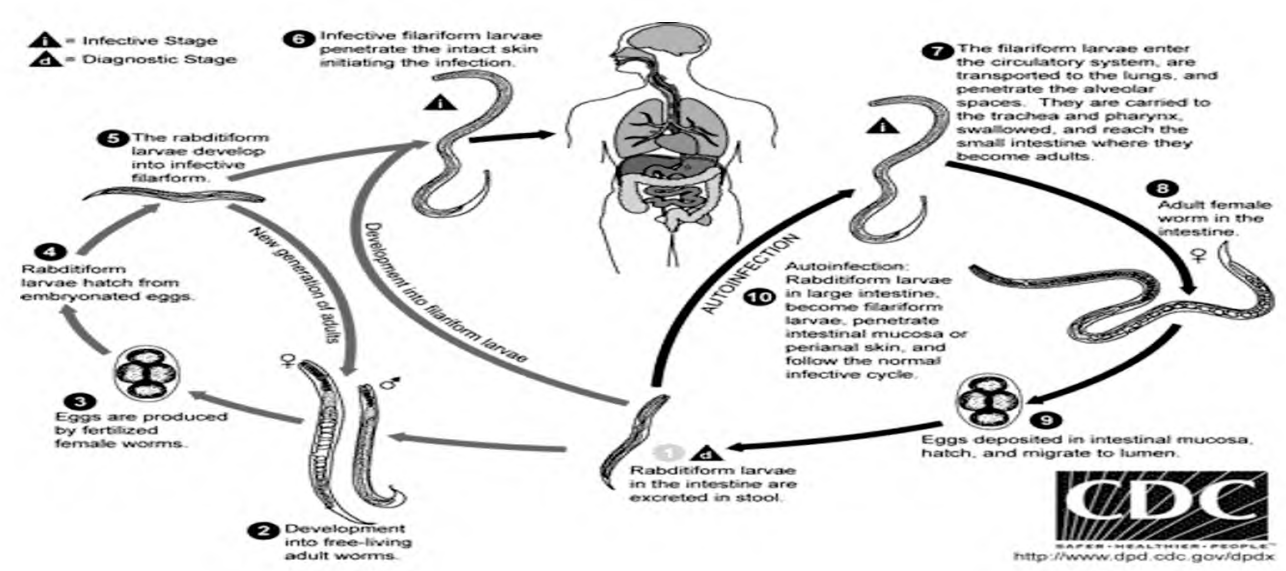

Fig. (2): Life cycle of strongyloide (http://www.dpd.cdc.gov/dpdx). 


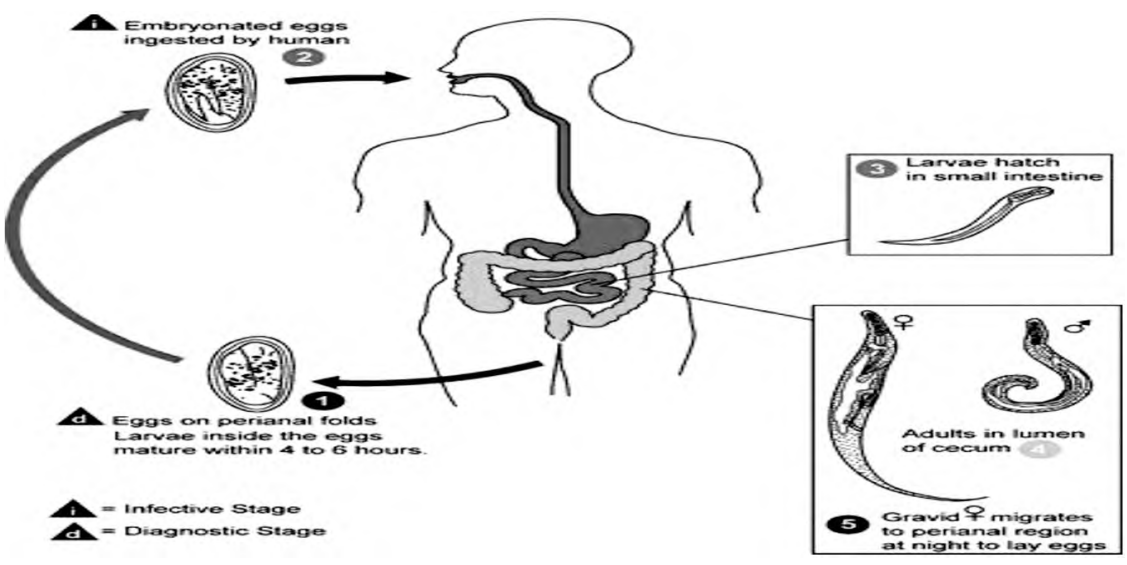

Fig. (3): Life cycle of E vermicularis (http://www.dpd.cdc.gov/ dpdx)

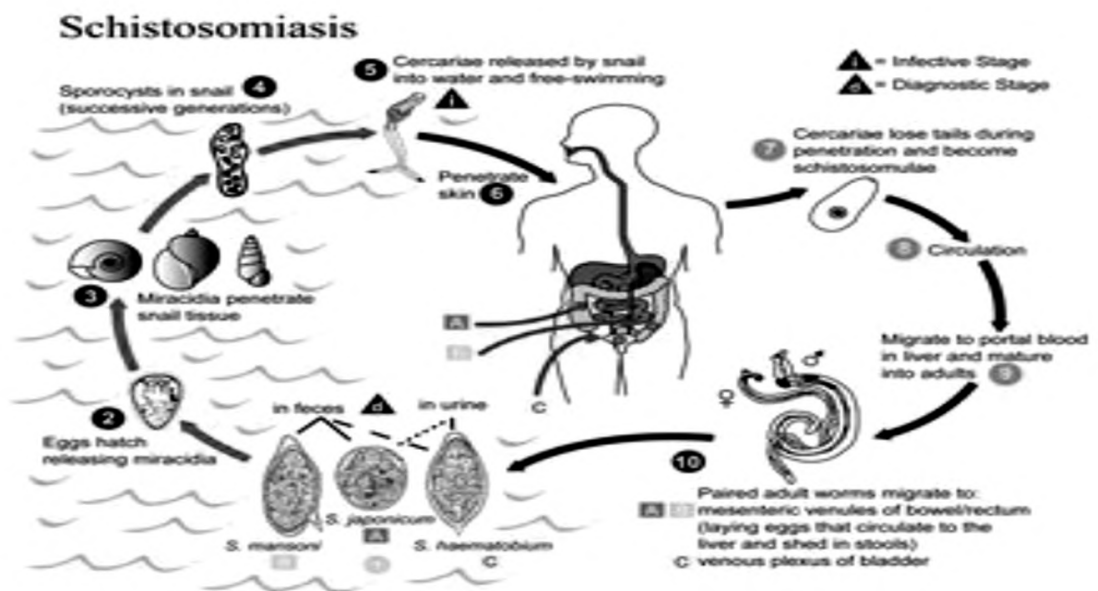

Fig. (4): Life cycle of schistosoma mansoni (http://www.dpd.cdc.gov/dpdx).

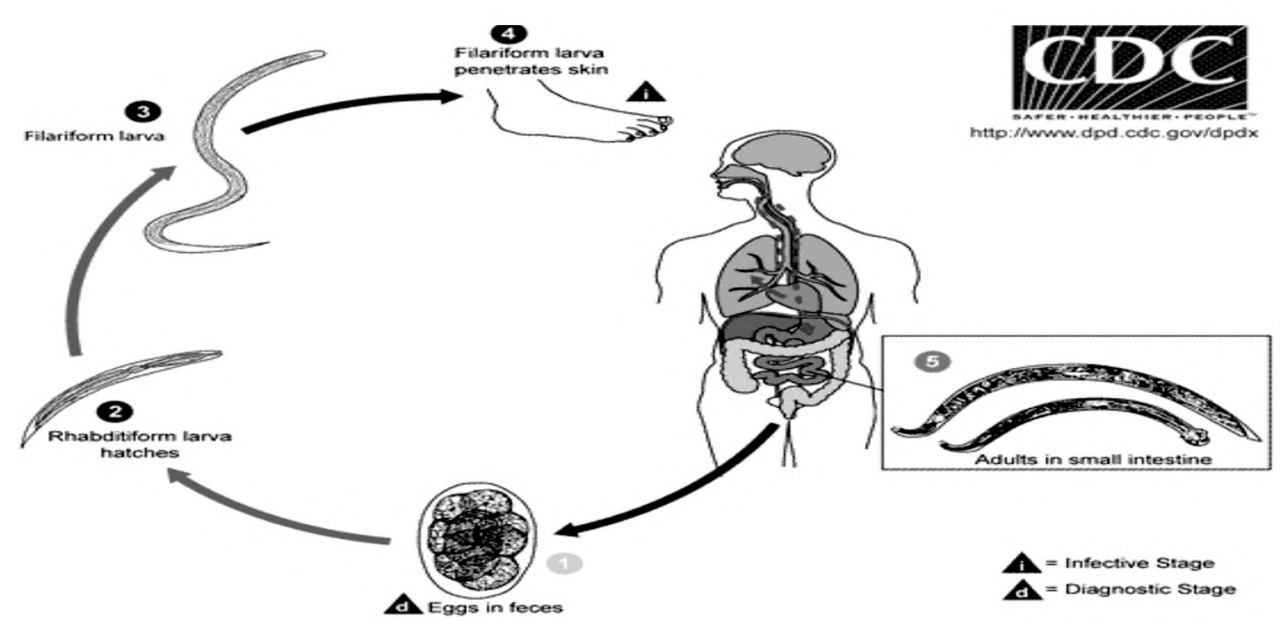

Fig. (5): Life cycle of anclystoma (http://www.dpd.cdc.gov/dpdx). 


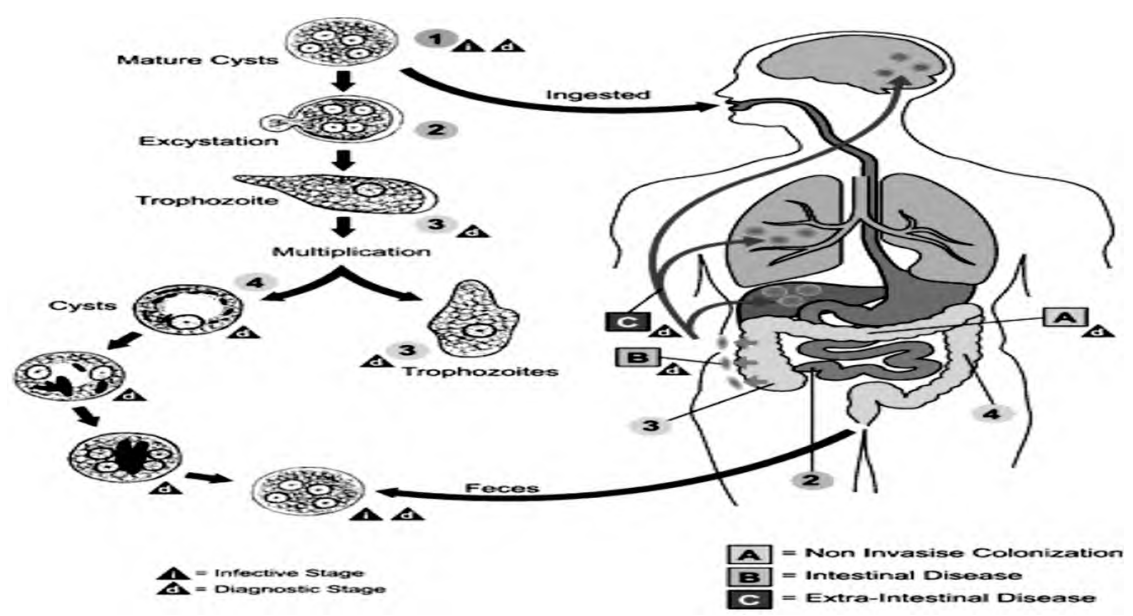

Fig. (6): Life cycle E histolytica (http://www.dpd.cdc.gov/dpdx).

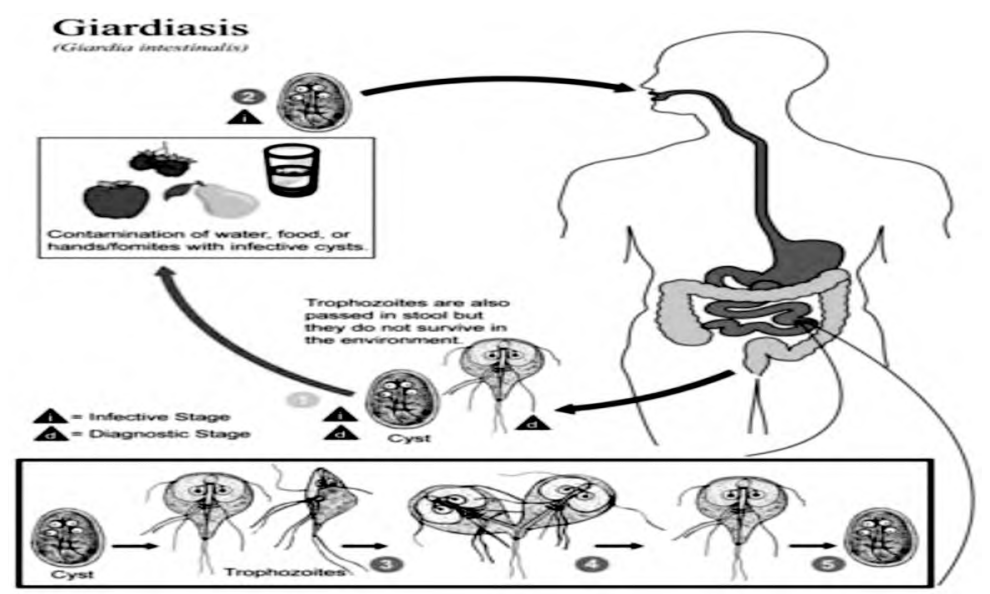

Fig. (7): Life cycle of giardia lambella (http://www.dpd.cdc.gov/dpdx).

\section{Patients and Methods}

This study was conducted on 1071 apparently healthy children aged from 6-12 years, 512 male and 559 female, who all were borne and living in Menoufiya Governorate, attending the primary schools in Shebin El Kom city from duration between the end of August 2016 to the end of November 2018 in Shebin El-Kom center and Berkit Sabaa village, Menoufiya Governorate. Two schools were selected from Shebin El-Kom city an one school from Berkit Sabaa village (357 students from each school) to show population in the Menoufiya Governorate and considered legible for entry into the study, if they met the following criteria; age between 6-12 years, born and live in Menoufiya Governorate and apparently healthy children. Children below the age 6 years or with any apparent disorders were excluded from the study. Legal permission was taken from the Ministry of education and school managers to collect urine, stool and blood samples and to assess school performance. Each student was subjected to full history taking, clinical examination, growth assess- ment; weight and height were assessed and were plotted on Egyptian growth charts and lastly laboratory investigations were also done included urine and stool analysis, hemoglobin level, rectal snip when needed. School performance was assessed through I.Q assessment using Arabic version of Stanford-binet intelligence scale the most common widely recommended fourth type of it, this test was done by psychologist, the result were interpreted as follows; child from (68-78) called slow learner, child from (79-88) called below average, child from (89-110) called average, child from (111-120) called above average, child from (121130) called excellent and lastly child from (131140) called Jennies [17].

School achievement was assessed taking average of marks of the three months of the first part of the year in which child under $50 \%$ called weak (feeble), child from (50\%-64\%) called acceptable, child from (65\%-74) called good, child from (75\%$84 \%$ ) called very good and child from (85\% to above) called excellent [18] 
Child school attendance taking average of attendance in the first part of year, (by using book of attendance and absence of students in the three months of the first term) ranging from; good attendance ( $90 \%$ to $100 \%$ ), average attendance (50\% to $90 \%$ ) and bad attendance (below 50\%) [19]

Child history was taken which included personal history; a standardized questionnaire to collect information about age, sex and occupation of the parents. Dietary history $f$ the child which was included eating habits and preference of special types of food as fresh vegetables, citrus fruits, canned food, shell fish, meat, take breakfast or not. Special habits of the child like any habits of medical importance such as smoking and drug abuse.

Child clinical examination, in which each child was submitted in complete clinical examination, included general examination, heart, chest and abdominal examination.

\section{Child anthropometric measurement which was included:}

Child body weight which is a growth parameter and a good index of acute and chronic nutritional status. Weight is evaluated for age and child height which was measured without the shoes and the child took a breath, relaxed, the shoulders were stretched up to be as tall as possible, then we put each child weight and height measurement of the children on Egyptian growth Charts (20012) which interpreted as followed; child below 3 rd Egyptian centile was considered below normal (abnormal), child between $3^{\text {rd }}$ and $97^{\text {th }}$ centile was considered normal and child above $97^{\text {th }}$ Egyptian centile: above normal (abnormal).

Laboratory examination of child blood, stool and urine samples in which all children were subjected to hemoglobin level estimation; which was assessed for every child using hemoglobin spectrophotometer (HemoCue, Sweden). Blood sample was performed on capillary blood from the fingertip of each child after discharge of the first drop by painless sterile safety blood lancets [20].

Child urine analysis was collected into clean plastic disposable cups with lids and was examined using the following method sedimentation method in which the terminal sample of urine was poured in a conical flask and left for 30-60 minutes to sediment; then the supernatant was discarded and a drop of the sediment was put on a slide and examined for the presence of parasites [21].
Child stool analysis in which stool sample was collected into clean dry plastic disposable cups with lids and examined using either direct smear method in which homogonous thin film was prepared on each slide by mixing the stool sample with a drop of normal saline or iodine solution the coarse fibers were removed away from the specimen and a cover glass was put on each preparation. The preparations were examined systematically using the low and high power of the microscope [22], or Sedimentation procedure in which stool sample was allowed to sediment for an hour and then decant the supernant and resuspended the sediment from the bottom layer, a pipette transfer two drops to a slide and cover with a cover glass and systematically examine the entire preparation. A negative report should not be made until the entire sediment has been examined [22] .

Child school performance assessment was divided into three assessments which were child psychometric assessment (assessment of intelligence quotient using Sanford-Binet test), child school attendance assessment (by using book of attendance and absence of students in the three months of the first term) and child school achievement assessment (by assessment of students; marks in the three months of the first term) [19]

Statistical analysis of the data were collected and analyzed using Epi-info version 6 and SPSS (Statistical Package for Social Science) version 22 in which Chi square test was used for qualitative data while student $t$-test was used for quantitative normally distributed and not normally distributed data and for all statistical tests done $p$-value of $<0.05$, was considered significant.

\section{Results}

Total screened children were 1071, $512(47.8 \%)$ were males, $559(52.2 \%)$ were females, 642 (59. 9\%) from 6-9 years and $429(40.1 \%)$ from 10-12 years. Pallor was found in $375(35.01 \%)$ and anemia was found in 395 (36.9\%) of children, 91 (8.5\%) of school children suffer from pruritis ani and no one of them had hepatosplenomegally and 668 $(62.4 \%)$ of them had parasitic infestation. The majority of screened school children were in average and below average sectors of IQ. The majority of children attend about $90-100 \%$ of school days, $54(5.04 \%)$ were attend between $(50-90 \%)$ of school days and the higher percent was for $>85 \%$ of school achievement and the majority of children were in between $50 \%-84 \%$ sectors of school achievement. In this study it was found that entameba histolytica 
is the most prevelant in (6-9y) followed by ascaris while the giardia is the most frequent infestation among the (10-12y) old group followed by Entameba histolytica and oxyuris. There was highly significant prevalence of entameba histolytica in young (6-9y) sector of age while there was highly significant prevalence of giardia and oxyuris in older (10-12y) sector of age, and there was no significant difference between other type of parasite regarding the age.

In this study it was found that the majority of non infected school children were non anemic and the number of anemic school children was significant higher in infected school children compared to non infected school children, and there was highly significance prevalence of pruritus ani in infected school children compared to non infected school children.

There was highly significant prevalence of below average sector (79-88) of IQ in infected children compared to non infected while there was significant prevalence of above average sector (111-120) of IQ in non infected compared to infected and with was no significant difference between infected and non infected in other sectors of IQ. The majority of infected and non infected school children are in the sector $(90 \%-100 \%)$ of school attendance. The number of non infected school children in the sector $(>85 \%)$ of school achievement is significant higher than those of infected in the same sector while the number of infected children in the sector $(<50 \%)$ of school achievement is significant higher than those of non infected in the same sector with no significant difference between infected and non infected in other sectors of school achievement.

The majority of anemic school children are in the below average sector (79-88) of IQ while the majority of non anemic school children are in the average sector (89-110) of IQ.

There was highly significant prevalence of sector (90-100\%) of School attendance in non anemic school children compared to anemic school children while there was highly significant prevalence of sector (50-90\%) of School attendance in anemic children compared to non anemic.

The majority of infected anemic school children were in the below average sector of IQ while majority of infected non anemic school children were in the average sector of IQ. The majority of infected anemic and infected non anemic school children are in the sector $(90 \%-100 \%)$ of school attendance and there was no significant difference between infected anemic and infected non anemic children regarding school attendance.

This table showed that there was a highly significance prevalence of non infected school children whom were young age (6-9ys) and female sex compared to infected school children while there was highly significance prevalence of infected school children whom were older age (10-12ys) and male sex compared to non infected school children.

This table showed that the majority of infected school children were in the below average sector of IQ while majority of non infected school children were in the average sector of IQ., there was no significant difference between infected and non infected regarding school attendance and the majority of infected and non infected school children are in the (>85) sector of school achievement.

This table showed that there was highly significant prevalence of above average sector (111-120) of IQ in non anemic children compared to anemic and there was no significant difference between anemic and non anemic in other sectors of IQ. The majority of anemic and non anemic school children are in the sector (90\%-100\%) of School attendance. The majority of anemic and non anemic school children are in (>85) sector of School achievement. There was significant higher than those of non anemic in the same sector and there was no significant difference between anemic and non anemic in other sectors of School achievement.

This table showed that the most prevalent type of infection in both anemic and non anemic children was entameba histolytica. There is highly significant prevalence of giardia and oxyuris in non anemic compared to anemic school children while there is highly significant prevalence of mixed infection and $h$ nana in anemic compared to non anemic school children and there is no significant difference between non anemic children and anemic regarding other types of parasites.

This table showed that there was highly significant prevalence of below Average sector (79-88) of IQ in infected anemic children compared to infected non anemic while there was significant prevalence of average sector (89-110) of IQ in infected non anemic compared to infected anemic and with was no significant difference between infected anemic and infected non anemic school children in other sectors of IQ. 
Table (1): Association between age group and type of parasitic infestation among the studied school children.

\begin{tabular}{|c|c|c|c|c|c|}
\hline \multirow{3}{*}{ Type of parasite } & \multicolumn{4}{|c|}{ Age in years } & \multirow{3}{*}{$p$-value } \\
\hline & \multicolumn{2}{|c|}{$\begin{array}{c}6-9 \\
(\mathrm{No}-344)\end{array}$} & \multicolumn{2}{|c|}{$\begin{array}{c}10-12 \\
(\text { No-324) }\end{array}$} & \\
\hline & $\mathrm{N}$ & $\%$ & $N$ & $\%$ & \\
\hline Entameba. histolytica & 151 & 43.8 & 68 & 20.9 & $<0.01$ \\
\hline Giardia & 42 & 12.2 & 89 & 27.4 & $<0.01$ \\
\hline Ascaris & 70 & 20.3 & 66 & 20.4 & $>0.05$ \\
\hline Oxyuris & 46 & 13.4 & 67 & 20.6 & $<0.05$ \\
\hline H nana & 1 & 0.29 & 2 & 0.61 & $>0.05$ \\
\hline Ttrichuris & 2 & 0.58 & 1 & 0.3 & $>0.05$ \\
\hline Anclystoma & 0 & 0.0 & 2 & 0.61 & $>0.05$ \\
\hline Stongyloide & 0 & 0.0 & 2 & 0.61 & $>0.05$ \\
\hline Schistosoma & 0 & 0.0 & 1 & 0.3 & $>0.05$ \\
\hline Mixed infection & 32 & 9.3 & 26 & 8.02 & $>0.05$ \\
\hline
\end{tabular}

Table (2): Comparison between infected and non infected school children regarding the demographic and clinical data.

\begin{tabular}{|c|c|c|c|c|c|}
\hline \multirow{2}{*}{ Type of variables } & \multicolumn{2}{|c|}{$\begin{array}{l}\text { Infected } \\
\text { (No-668) }\end{array}$} & \multicolumn{2}{|c|}{$\begin{array}{l}\text { Non infected } \\
(\text { No-403) }\end{array}$} & \multirow{2}{*}{$p$-value } \\
\hline & $\mathrm{N}$ & $\%$ & $\mathrm{~N}$ & $\%$ & \\
\hline Age (years) $\mathrm{X} \pm \mathrm{SD}$ & \multicolumn{2}{|c|}{$9.36 \pm 2.45$} & \multicolumn{2}{|c|}{$8.75 \pm 2.08$} & $<0.01$ \\
\hline $\begin{array}{l}\text { Gender: } \\
\quad \text { Male } \\
\text { Female }\end{array}$ & $\begin{array}{l}379 \\
289\end{array}$ & $\begin{array}{l}56.7 \\
43.3\end{array}$ & $\begin{array}{l}133 \\
270\end{array}$ & $\begin{array}{l}33.1 \\
66.99\end{array}$ & $<0.01$ \\
\hline $\begin{array}{l}\text { Body weight centile: } \\
<\text { rd } \\
\text { 3rd-97th } \\
>97 \text { th } \\
\text { X } \pm \text { SD }\end{array}$ & $\begin{array}{l}107 \\
552 \\
9 \\
27.3\end{array}$ & $\begin{array}{l}16.01 \\
82.6 \\
1.3 \\
+3.82\end{array}$ & $\begin{array}{l}47 \\
340 \\
16 \\
29.6\end{array}$ & $\begin{array}{l}11.6 \\
84.4 \\
3.9 \\
+4.13\end{array}$ & $\begin{array}{l}<0.05 \\
>0.05 \\
<0.05 \\
<0.01\end{array}$ \\
\hline $\begin{array}{l}\text { Height centile: } \\
\text { 3rd } \\
\text { 3rd-97th } \\
>97 \text { th } \\
\quad \mathrm{X} \pm \mathrm{SD}\end{array}$ & $\begin{array}{l}31 \\
624 \\
13 \\
126.0\end{array}$ & $\begin{array}{l}4.7 \\
93.4 \\
1.9 \\
+12.37\end{array}$ & $\begin{array}{l}21 \\
370 \\
12 \\
127.4\end{array}$ & $\begin{array}{l}5.2 \\
91.8 \\
2.9 \\
+12.85\end{array}$ & $>0.05$ \\
\hline $\begin{array}{l}\text { Anemia: } \\
\text { Present } \\
\text { Absent }\end{array}$ & $\begin{array}{l}271 \\
397\end{array}$ & $\begin{array}{l}40.5 \\
59.5\end{array}$ & $\begin{array}{l}124 \\
279\end{array}$ & $\begin{array}{l}30.8 \\
69.2\end{array}$ & $<0.01$ \\
\hline $\begin{array}{c}\text { Pruritis ani: } \\
\text { Present } \\
\text { Absent }\end{array}$ & $\begin{array}{l}88 \\
580\end{array}$ & $\begin{array}{l}13.2 \\
86.8\end{array}$ & $\begin{array}{l}3 \\
400\end{array}$ & $\begin{array}{l}0.07 \\
99.3\end{array}$ & $<0.01$ \\
\hline
\end{tabular}

Table (3): Comparison between infected and non infected school children regarding IQ, school attendance and achievement.

\begin{tabular}{|c|c|c|c|c|c|}
\hline & \multicolumn{2}{|c|}{$\begin{array}{l}\text { Infected } \\
\text { (No-668) }\end{array}$} & \multicolumn{2}{|c|}{$\begin{array}{l}\text { Non infected } \\
(\text { No-403) }\end{array}$} & \multirow{2}{*}{$\begin{array}{c}p- \\
\text { value }\end{array}$} \\
\hline & $\mathrm{N}$ & 06 & $\mathrm{~N}$ & $\%$ & \\
\hline \multicolumn{6}{|l|}{ School children IQ: } \\
\hline Excellent (121-131) & 1 & 0.14 & 2 & 0.4 & $>0.05$ \\
\hline $\begin{array}{l}\text { Above average } \\
(111-120)\end{array}$ & 84 & 12.5 & 73 & 18.1 & $<0.05$ \\
\hline Average (89-110) & 252 & 37.7 & 164 & 40.6 & $>0.05$ \\
\hline Below average (79-88) & 289 & 43.2 & 138 & 34.2 & $<0.01$ \\
\hline Slow learner $(68-78)$ & 42 & 6.2 & 26 & 6.4 & $>0.05$ \\
\hline \\
\hline$(50-90 \%)$ & 37 & 5.5 & 17 & 4.2 & \\
\hline \multicolumn{6}{|l|}{ School achievement: } \\
\hline$(>85 \%)$ & 251 & 37.5 & 176 & 41.4 & $<0.05$ \\
\hline$(75 \%-84 \%)$ & 175 & 26.1 & 104 & 25.8 & $>0.05$ \\
\hline$(65 \%-74 \%)$ & 149 & 22.3 & 75 & 18.6 & $>0.05$ \\
\hline$(50 \%-64 \%)$ & 56 & 8.3 & 42 & 4.04 & $>0.05$ \\
\hline$(<50 \%)$ & 37 & 5.5 & 6 & 1.4 & $<0.01$ \\
\hline
\end{tabular}

Table (4): Comparison between anemic and non anemic school children regarding IQ, school attendance and achievement.

\begin{tabular}{|c|c|c|c|c|c|}
\hline & \multicolumn{2}{|c|}{$\begin{array}{l}\text { Anemic } \\
\text { (No-395) }\end{array}$} & \multicolumn{2}{|c|}{$\begin{array}{l}\text { Non anemic } \\
\text { (No-676) }\end{array}$} & \multirow{2}{*}{$\begin{array}{c}p- \\
\text { value }\end{array}$} \\
\hline & $\mathrm{N}$ & 6 & $\mathrm{~N}$ & $\%$ & \\
\hline \multicolumn{6}{|l|}{ School children IQ: } \\
\hline Excellent (121-131) & 0 & 0.0 & 1 & 0.15 & $>0.05$ \\
\hline $\begin{array}{l}\text { Above average } \\
(111-120)\end{array}$ & 15 & 3.8 & 53 & 7.8 & $<0.01$ \\
\hline Average (89-110) & 160 & 40.5 & 292 & 43.0 & $>0.05$ \\
\hline Below average (79-88) & 179 & 45.3 & 271 & 40.1 & $<0.05$ \\
\hline Slow learner (68-78) & 41 & 10.4 & 59 & 8.7 & $>0.05$ \\
\hline \multicolumn{6}{|l|}{ School attendance: } \\
\hline$(90-100 \%)$ & 378 & 95.7 & 671 & 99.3 & $>0.01$ \\
\hline$(50-90 \%)$ & 17 & 4.3 & 5 & 0.7 & \\
\hline \multicolumn{6}{|l|}{ School achievement: } \\
\hline$(>85 \%)$ & 110 & 27.8 & 238 & 35.2 & $<0.05$ \\
\hline$(75 \%-84 \%)$ & 89 & 22.5 & 186 & 27.5 & $>0.05$ \\
\hline$(65 \%-74 \%)$ & 102 & 25.8 & 140 & 20.7 & $>0.05$ \\
\hline$(50 \%-64 \%)$ & 55 & 13.9 & 74 & 10.9 & $>0.05$ \\
\hline$(<50 \%)$ & 39 & 9.8 & 38 & 5.6 & $<0.01$ \\
\hline
\end{tabular}

Table (5): Difference between different types of parasite in relation to Anemia.

\begin{tabular}{llllllc}
\hline & \multicolumn{2}{c}{$\begin{array}{c}\text { Anemic } \\
(\text { No-246) }\end{array}$} & & \multicolumn{2}{c}{$\begin{array}{c}\text { Non anemic } \\
(\text { No-422) }\end{array}$} & $\begin{array}{c}p- \\
\text { value }\end{array}$ \\
\cline { 2 - 3 } & $\mathrm{N}$ & $\%$ & & $\mathrm{~N}$ & $\%$ & \\
\hline Ent. Histo & 80 & 32.5 & & 139 & 32.9 & $>0.05$ \\
Ascaris & 49 & 19.9 & & 87 & 20.6 & $>0.05$ \\
Giardia & 31 & 12.6 & & 100 & 23.7 & $<0.01$ \\
Oxyuris & 26 & 10.6 & 87 & 20.6 & $<0.01$ \\
H nama & 3 & 1.2 & & 0.0 & $<0.05$ \\
Ancylstoma & 2 & 0.8 & & 0 & 0.0 & $>0.05$ \\
Trichuris .T & 2 & 0.8 & & 0.24 & $>0.05$ \\
Strongyloide & 2 & 0.8 & 0 & 0.0 & $>0.05$ \\
Schistosoma & 1 & 0.4 & 0 & 0.0 & $>0.05$ \\
Mixed & 50 & 20.3 & 8 & 1.9 & $<0.01$ \\
\hline
\end{tabular}

Table (6): Comparison between infected anemic and infected non anemic school children regarding IQ, school attendance and achievement.

\begin{tabular}{|c|c|c|c|c|c|}
\hline & \multicolumn{2}{|c|}{$\begin{array}{l}\text { Anemic } \\
\text { (No-271) }\end{array}$} & \multicolumn{2}{|c|}{$\begin{array}{l}\text { Non anemic } \\
(\text { No-397) }\end{array}$} & \multirow{2}{*}{$\underset{p-}{p-}$} \\
\hline & $\mathrm{N}$ & $0 / 0$ & $\mathrm{~N}$ & $\%$ & \\
\hline \multicolumn{6}{|l|}{ School children IQ: } \\
\hline Excellent (121-131) & 0 & 0.0 & 1 & 0.02 & $>0.05$ \\
\hline $\begin{array}{l}\text { Above average } \\
(111-120)\end{array}$ & 30 & 11.1 & 54 & 13.6 & $>0.05$ \\
\hline Average (89-110) & 90 & 33.2 & 162 & 40.8 & $<0.05$ \\
\hline Below average (79-88) & 131 & 48.3 & 148 & 37.3 & $<0.01$ \\
\hline Slow learner (68-78) & 20 & 7.4 & 32 & 8.1 & $>0.05$ \\
\hline \multicolumn{6}{|l|}{ School attendance: } \\
\hline$(90-100 \%)$ & 215 & 79.3 & 328 & 82.6 & $>0.05$ \\
\hline$(50-90 \%)$ & 56 & 20.7 & 69 & 17.4 & \\
\hline
\end{tabular}




\section{Discussion}

The overall average parasitic infestation rate in schools of Shebin El-Kom Menoufiya Governorate could be very high. Given that the 357 children examined per school were randomly selected, an overall average infestation rate of $65.7 \%$ in the sample is exceptionally high. Such factors mentioned above that characterize the region are ideal for parasitic prevalence. Ascariasis, and the hookworm diseases are geo-mediated infestations whose endemicity is facilitated by number of factors, such as climatic factors, including high temperatures, and heavy precipitation. These two factors account for high humidity, the single most important parameter that favours the hatchability of geohelminth ova in the soil [23].

The prevalence of the protozoa parasites among the children is seemingly low. This could be explained by the method used to process faecal materials. The majority of the identifiable motile trophozoites could have been destroyed during concentration of the stool samples. The method of direct examination of wet stool would have probably revealed more E. histolytica and G. lamblia [24].

For S. mansoni boys are more affected compared to girls and this could be attributed to swimming in the rivers, a common behavioural risk factor in boys at this age, where they would interact with the infective cercariae. Elsewhere, such activities and situations like swimming, fishing, watering of animals, swamp/wetland rice growing, have been identified as critical in schistosomiasis epidemiology $[25,26]$.

The hookworm infection rate of 2.73 per cent is indica-tive of lack of footwear amongst the pupils. Indeed, the people are poor and children walk bare-footed through the bush paths from their villages to schools. It is also indicative of the unsanitary fecal disposal methods of the population. The high rate of ingested parasites such as E. histolytica, G. lamblia and round-worm is a direct result of the unsanitary conditions around the homes of the people since sanitary facili-ties at the schools were adequate and well used. Sanitary facilities in the homes are inadequate to the majority of the people, particularly in Aluru parish through which Ebihwa River runs, and where latrines are scarce. Similar observations were made by [27] in Tanzania and Nigerian villages, respectively.
Kabatereine et al., (1997) recorded other human in-testinal parasites in primary schools of Kampala city, including Trichuris trichiura, Strongyloides stercolaris, Taenia sp. and Enterobius vermicularis. These have not been identified in the present study. This could be explained by the fact that Kampala, as a capital city, receives people from various areas, both nationally and internationally searching for different opportunities unlike Moyo, which is relatively localised. Periodic migration of people from Nyanza region of western Kenya to Kampala had earlier been identified as the most important epidemiological factor for persistence of hookworm infestation in Kampala [29]. Also, periodical movement of pupils during school holidays to their western Kenya upcountry homes from Nairobi city were shown to lead to their re-infestation with hookworm and T. trichiurai [30]

There is no distinct reason to account for the differences in parasitic distribution in the different schools, because both environmental and socio-economic and cultural conditions appear similar. Moreover, there is no significant difference in parasitic prevalence in the different schools.

Other studies have shown a functional relationship between sex and parasite infestation [31], sex has been found significant in this study, ( $p$-value $<0.01)$.

The presence of intestinal parasites together affected school performance. A cumulative burden of parasitism meaningfully affected school performance due to their synergistic action. This finding was consistent with a study conducted in the South Gondar Zone of Tach-Gayint Woreda, in Arb-Gebeya Town that the presence of parasites affects academic performance among the junior secondary school children in in Arb-Gebeya Town in Ethiopia during the school year 2007 [32]. Of the 1071 children studied, $65.7 \%$ harbored parasites. Children free of parasitic infections obtained higher grades than the infected group. This difference was of statistical significance. The teachers in charge of the treated group noted that a significant improvement in school performance following treatment [32]. Another study in Jamaica had also found similar results. In one school of Jamaican children who were treated for moderate whipworm infections had test scores, that lagged by $15 \%$, up to the level of uninfected children [33]. Another study in Jamaican children aged between 9-12 years showed that treatment of T. trichiura infection showed significant improvements in the result of 
tests of the auditory, short term memory and scanning and retrieval of long-term memory. Nine weeks after treatment, previously infected children performed as well as uninfected children [33].

Hookworm infection is causally linked to anaemia in humans [34]. The prevalence in this study was $40.5 \%$ in presence of parasitic infestation. This rate is higher than that reported by Favour $\mathrm{O}$. and co-authors 2011 among children in Edo State, Nigeria, who reported that 222 (70.2\%) out of 316 samples examined were positive for hookworm, but less than that reported by Agbolade et al., 2007, where school children attending public schools in Ijesha-Ijebu and Okun-owa in Ogun State had a prevalence of $90(17 \%)$ out of 1,059 subjects sampled and Nmorsi et al., 2009 where preschool children in Akoko-Edo, Edo state had a prevalence of $65.7 \%$. Whether or not a person with hookworm infection develops anaemia depends on the worm species and load, duration of infection, body iron stores, dietary intake and absorption, and physiological iron requirement. A low hookworm load can cause anaemia in people whose intake of iron is low and whose iron stores are already depleted [38]. In this study, considering hookworm as an independent risk factor for anaemia, there was a significant association between hookworm and anaemia status. This report agrees with previous studies of Stoltzfus et al., 2004, but disagrees with that of Hung et al., 2005 where no association was established between hookworm infection and anaemia among children of ethnic minority of Phan tien village in Vietnam.

Moderate or high intensity Trichuris infections are also associated with anaemia [41]

Other studies have used height, weight or haemogblobin concentrations as indices to assess the nutritional status of parasite-infected children and children treated for parasites, and show a remarkable improvement in haemoglobin status in children given iron supplementation, thus reiterating the contribution of worm infestation to childhood malnutrition [42]

\section{Conclusion and recommendations}

Socio-economics, topography and climatic factors, like elsewhere, seem to promote the helminthic prevalence than any other factors. In view of their role in causing anaemia and retarding academic performance, comprehensive investigations of intestinal parasites of in the schools of the entire Egypt country need to be carried out.

\section{References}

1- ANDERSON R., BUNDY D., DAVIS A. and HENDERSON D.: Epidemiology and control of intestinal parasites with nitazoxanide in children. Am. J. Trop. Med. Hyg. Apr., 68 (4): 3 84-5. 13, 2002.

2- DANIEL, DICKSON R., AWASTHI S., DEMELLWEEK C. and WILLIAMSON P.: Anthelmintic drugs for treating worms in children: Effects on growth and cognitive performance. Cochrane Database Syst., 10-71, 2004.

3- POLLITT E., HATHIRAT P., KOTCHABHAKDI N.J. and MISSELL L.: Effects of a diet deficient in iron on the growth and development of preschool and schoolaged children. Food and Nutrition Bulletin, 13: 110-18, 1991.

4- EZENKWELE, NAHIMANA S. and GRSEELS B.: Comparison of the direct faecal smear and two thick smear techniques, the diagnosis of intestinal parasitic infections. Trop. Med. Hyg., (12): 523-525, 2004.

5- ELGART G.W., MEINKING T.L., FINAN R. and ZOUROB D.: Adverse reactions after large-scale treatment of onchocerciasis with ivermectin: combined results from eight community trials. Bull. World Health. Organ., 67 (6): 707-19, 2004.

6- SONG H.J., CHO C.H. and KIM J.S.: Prevalence and risk factors for enterobiasis among preschool children in a metropolitan city in Korea. Parasitol. Res., 91 (1): 46-50, 2003.

7- KHUROO M.S., ZARQAR S.A., YATTOO G.N., KOUL P., KHAN B.A. and DAR M.Y.: Ascaris induced Acute Pancreatitis. "Fatal human ascariasis following secondary massive infection". Am. J. Trop. Med. Hyg., 35 (2): 3 148, 1997.

8- PICKERING, PALAU L.A. and PANKEY G.A.: Strongyloides hyperinfection in a renal transplant recipient receiving cyclosporine: Possible by kidney transplant. Am. J. Trop. Med. Hyg., 57 (4): 413-5, 2004.

9- MONIS T.D., OBERHELMAN R.A., MCGREGOR S and ANI C.: Antiparasitic therapy in children. Pediatr. Clin. North. Am., 52 (3): 917-48, viii, 2003.

10-WELLS G.J. and STEIN J.: Changes in circulating parasite antigen levels after treatment of bancroftian filariasis with diethylcarbamazine and ivermectin. J. Infect. Dis., 224: 143,2000

11-BOYCE W.T., ESSEX M.J. and WOODWARD H.R.: The confluence of mental, physical, social, and academic difficulties in middle childhood: Exploring the head waters of early life morbidities. J. Am. Acad. Child. Adolesc. Psychiatry, $41: 580-587,2002$.

12- WILLIAMS J., KLINEPETER K. and PALMES G. Diagnosis and treatment of behavioral health disorders in pediatric practice. Pediatrics, 14: 601-606, 2004.

13- SILVA DE N.R., BROOKER S., HOTEZ P.J., MONTRESOR A. and FENGELS D.: Soil transmitted helminthes infections: Updating the global picture. Trend. Parasitol., 19: 547-551, 2003.

14- ALCOCK, KAND J., BUNDY D.A.P., et al.: The impact of infectious disease on cognitive function. Environmental Effect on Cognitive Ablates, 221-253, 2001.

15- MUNIZ P.T., FERRERIA M.U. , FERRERIA G.S., TIONDE W.L. and MONTERIO C.G.: Intestinal parasite 
infections in young children in Sao Paulo, Brazil; Prevalences, temporal trends and associations with physical growth. Ann. Trop. Med. Parasitol., 96: 503-12, 2002.

16- BLEAKLEY H.: Disease and development. Evidence from the American South. J. Eur. Econ. Assoc., 1: 376386, 2003.

17- KIHLSTROM J. and CANTOR N.: Social intelligence. In Sternberg R.J., Editor, Handbook of intelligence, Cambridge Univ. Press, New York, pp. 359-379. 2000.

18-BARBER M., GOUGH G. and JOHNSON M.: Promoting successful schooling: The development of a school improvement index and the use of pupil and parent surveys. A Report to the Association of London Authorities, Vol. 25, pp. 56-68, 1994.

19- CUTTANCE P.: Quality assurance reviews as a catalyst for school improvement in Australia. In Hargreaves, A., Lieberman A., Fullan M. and Hopkins D. (Eds.) International handbook of educational change. Dordrecht, The Netherlands: Kluwer Academic Publishers, 31: 955-960, 1998.

20- CHERNECKY C.C., BERGER B..J, CHEEVER A.W and KFAND WYNN T.A.L.: Laboratory Tests and Diagnostic Procedures, 4th ed. Philadelphia: Saunders, 7: 178181,2004

21- FISCHBACH F.T., DUNNING M.B., VERGELY O. and DANIS M.: Manual of Laboratory and Diagnostic Tests, 7th ed. Philadelphia: Lippincott Williams and Wilkins, 5.512-530, 2004.

22- PAGANA K.D.: Mosby's Manual of Diagnostic and Laboratory Tests, ${ }^{2}$ ed. St. Louis: Mosby, 257-272, 2002 .

23- ZIBAEI M. and SADJJADI S.M.: Prevalence of helminth ova in soil samples from public places in Shiraz. East. Mediterr. Health J., 16 (5): 580, 2010.

24- FRIPP P.J.: Introduction to human parasitology with reference to Southern Africa. ${ }^{\text {ro }}$ ed. Macmillan South African Publishers (pty) Ltd. Johannesburg. South Africa, 1995.

25- HIGHTON R.B.: Schistosomiasis. In: Vogel L.C., Muller A.S., Odingo R.S., Onyango Z. and De Geus A. Health and Disease in Kenya. East African Literature Bureau. Nairobi. Der es Salam. Kampala, pp., 347- 355, 1974.

26- ARINOLA O. and FAWOLE O.: Age and sex graded helminth infection in a Nigerian village. East Africa Medical Journal, 72 (2): 110-112, 1995.

27- JACOBSON R.J.: The incidence of intestinal and urinary parasites among a selected population from the eastern Usambaras, Tanzania. In: Enderson C. and Kilama W. L. (ed) (1974). Parasitoses of Man and animals in Africa. East African Literature Bureau Nairobi. Der es Salam. Kampala, pp. 299-303, 1974.

28- KABATEREINE N.B., KEMIJUMBI J., KAZIBWE F. and ONAPA A.W.: Human intestinal parasites in Primary School Children in Kampala, Uganda. East Af-rican Medical Journal, 74 (5): 311-314, 1997.

29- Kakande M.I.: A survey of intestinal helminths in two urban communities. East African Medical Journal, 48 (8): 438-446, 1971
30- WIJERS D., J.B. KINYANJUI H. and RIJPSTRA A.C. Intestinal parasites found in children attending a school in Bahati (Nairobi). East African Medical Journal, 49 (12): 989-995, 1972.

31- ALBONICO M., CHWAYA H.M., MONTRESOR A. and STOLFZFUS R.J.: Parasitic infection in Pemba schoolchildren. East Africa Medical Journal, 74 (5): 294-298.

32- AMHA ADMASIE, AHMED ALI and ABERA KUMIE: Assessment of demographic, health and nutrition related factors to a school performance among school children in Arb-Gebeya Town, Tach-Gaynt Woreda, South Gondar, Ethiopia. Ethiop. J. Health. Dev., 27 (2): 104-110, 2013.

33- World Health Organization. Prevention and control of schistosomiasis and soil-transmitted helmenths No 912. Geneva, WHO, 2002.

34- HOTEZ P.J. and MOLYNEUX D.H.: One of Africa's Great Killers and a Rationale for linking Malaria and Neglected Tropical diseases control to achieve a Common Goal. Plos. Negl. Trop. Dis., 2: 270-274, 2008,

35- FAVOUR O., OGUNTADE M. and PAUL I.: A significant association between intestinal helminth infection and anaemia burden in children in rural communities of Edo state, Nigeria. N. Am. J. Med. Sci., 3 (1): 30-34, 2011.

36- AGBOLADE O.M., AGU N.C., ADESANYA O.O., ODEJAYI AO., ADIGUN A.A., ADESANLU E.B., e al.: Intestinal helminthiasis and Schistosomiasis among school children in an urban center and some rural communities in southwest Nigeria. Korean. J. Parasitol., 45: 233-238, 2007.

37- NMORSI O.N.G., ISAAC C., AASHIKPELOKHAI S.I. and UKWANDU N.D.: Geohelminthiasis among Nigerian preschool age children. International J. Med. Sci., 10: 407-411, 2009.

38- HOTEZ P.J., BETHONY J., BOTTAZZI M.E., BROOKER S. and BUSS P.: Hookworm: The Great Infection of Mankind. Plos. Med., 2: 67-70, 2005.

39- STOLTZFUS R.J., CHWAYA H.M., MONTRESSOR A., TIELSCH J.M., JAPE J.K., ALBONICO M., et al.: Low dose daily iron supplementation improves iron status and appetite but not anaemia, whereas quarterly anthelminthic treatment improves growth, appetite and anemia in Zanzibari preschool children. J. Nutr., 134: 348-356, 2004.

40- HUNG L.Q., GIAO P.T., PETER V. and BINH T.Q.: Anaemia, malaria and hookworm infections in a Vietnamese ethnic minority. Southeast Asian. J. Trop. Med. Pub. Health, 36: 234-237, 2005.

41- BROOKER S., AKHWALE W., PULLAN R., ESTAMBALE B. and CLARKE SE.: Epidemiology of Plasmodium-Helminth co-infection in Africa: Populations at risk, potential impact on anaemia and prospects for combining control. Am. J. Trop. Med. Hyg., 77: 88-98, 2007.

42- ALBONICO M., ALLEN H., CHITSULO L., ENGELS D., GABRIELLI F. and SAVIOLI L.: Controlling Soil Transmitted helminthiasis in pre-school age children through preventive chemotherapy. Plos. Negl. Trop. Dis., 34: 234-238, 2008 


\section{تدهور الأداء المدرسى نتيجة الإصابة الطفيلية

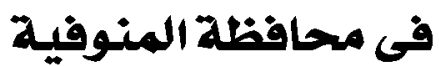

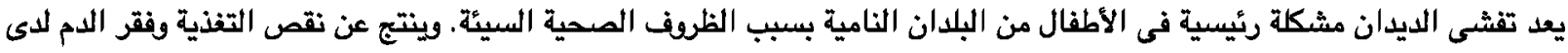

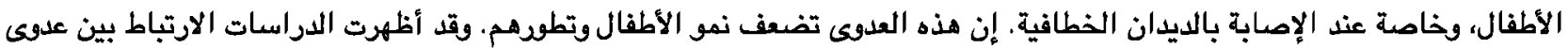

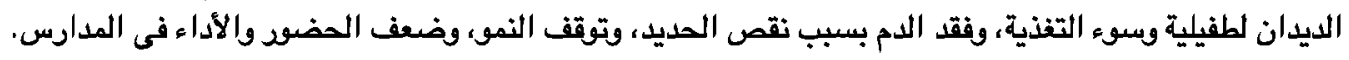

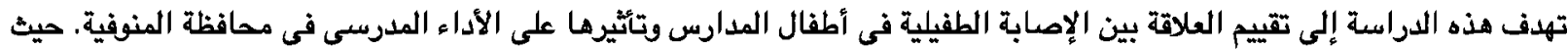

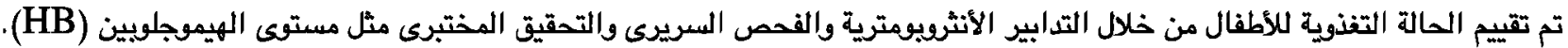

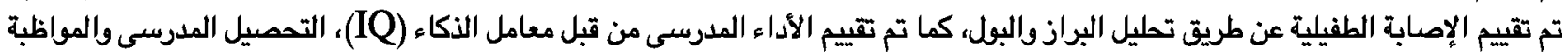

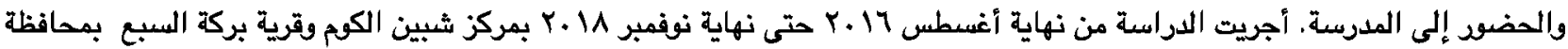
المنوفية .

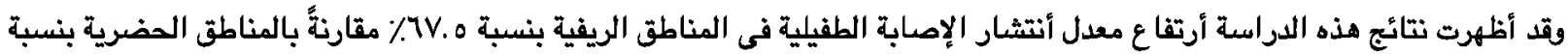

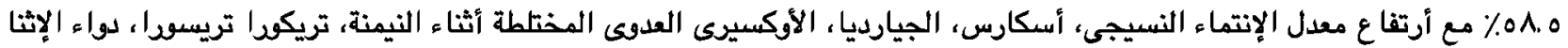

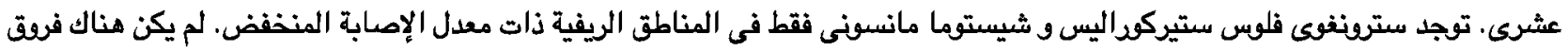

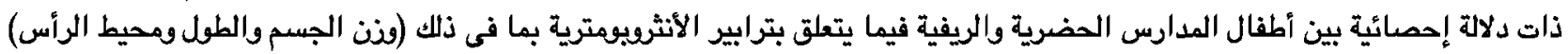

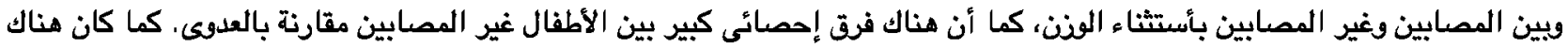

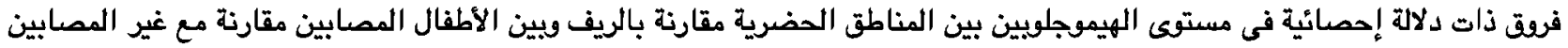

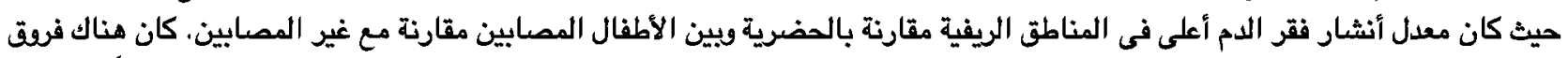

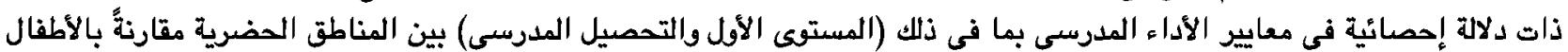

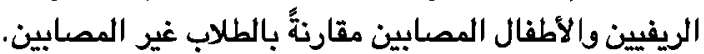

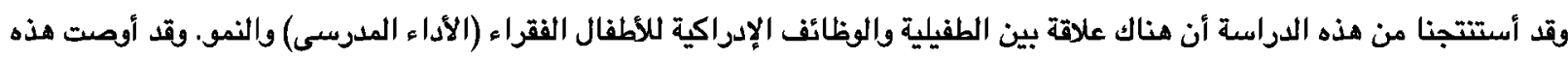

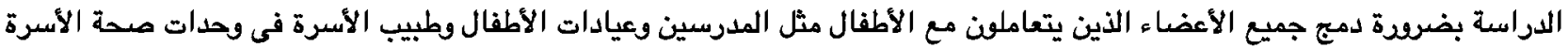

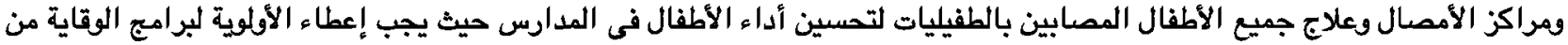

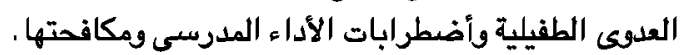

